\title{
Madridge
}

ma publisters 9 Journal of Nanotechnology \& Nanoscience

Clinical Image Article

Open Access

\section{Therapeutic Nanomedicine Different High-Resolution Experimental Images and Computational Simulations for Human Brain Cancer Cells and Tissues Using Nanocarriers Deliver DNA/RNA to Brain Tumors under Synchrotron Radiation with the Passage of Time Using Mathematica and MATLAB}

Alireza Heidari*

Faculty of Chemistry, California South University, 14731 Comet St. Irvine, CA 92604, USA

\section{Article Info}

*Corresponding author:

Alireza Heidari

Faculty of Chemistry

California South University

14731 Comet St. Irvine

CA 92604, USA

E-mail: Scholar.Researcher.Scientist@gmail.com Alireza.Heidari@calsu.us

Received: October 31, 2017

Accepted: November 17, 2017

Published: November 24, 2017

Citation: Heidari A. Therapeutic Nanomedicine Different High-Resolution Experimental Images and Computational Simulations for Human Brain Cancer Cells and Tissues Using Nanocarriers Deliver DNA/RNA to Brain Tumors under Synchrotron Radiation with the Passage of Time Using Mathematica and MATLAB. Madridge J Nanotechnol Nanosci. 2017; 2(1): 76-82.

doi: 10.18689/mjnn-1000114

Copyright: ( $) 2017$ The Author(s). This work is licensed under a Creative Commons Attribution 4.0 International License, which permits unrestricted use, distribution, and reproduction in any medium, provided the original work is properly cited.

Published by Madridge Publishers
Keywords: Nanomedicine; Vancer cells; Tissue; Nanocarrier.

\section{Description of Images}

In the current study, first, we have experimentally presented therapeutic nanomedicine different high-resolution experimental images for human brain cancer cells and tissues using nanocarriers deliver DNA/RNA to brain tumors under synchrotron radiation with the passage of time (Figure 1) [1-101]. Also, different computational simulations of human brain cancer cells and tissues translational Nano drugs delivery treatment process under synchrotron radiation with the passage of time was computationally investigated using Mathematica and MATLAB (Figure (2) [1-101]. It is clear that malignant human brain cancer cells and tissues have gradually transformed to benign human brain cancer cells and tissues under synchrotron radiation with the passage of time (Figures 1 and 2)) [1-101].

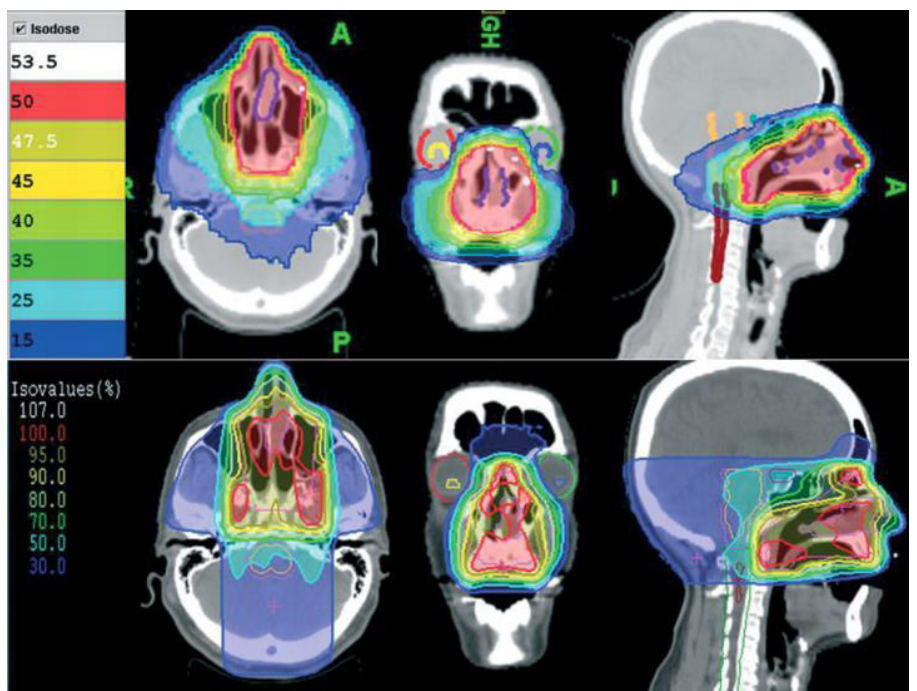



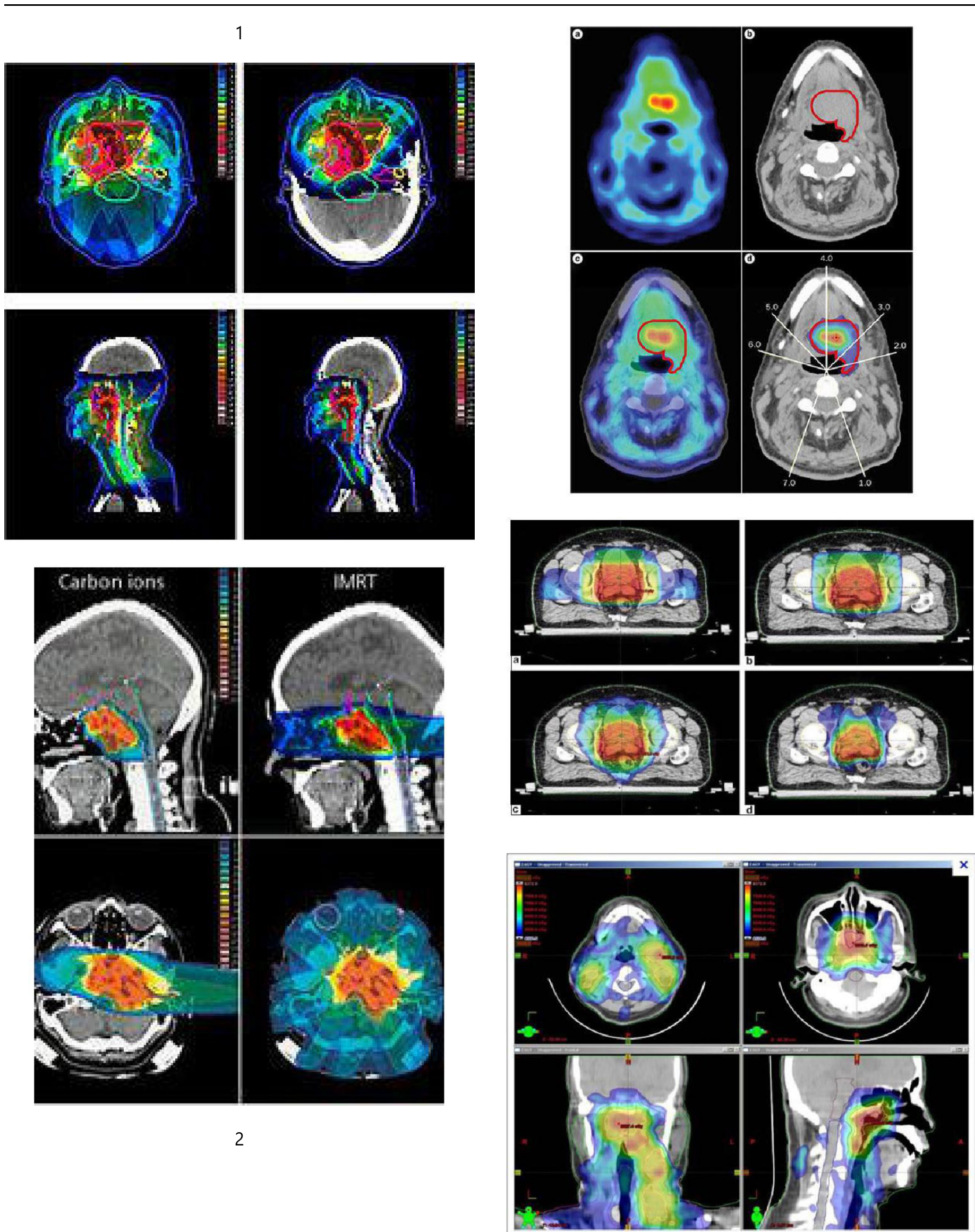
Figure 1. Experimental results of different high-resolution images of human brain cancer cells and tissues translational Nano drugs delivery treatment process under synchrotron radiation with the passage of time [1-101].

Furthermore, we have computationally simulated human brain cancer cells and tissues translational Nano drugs delivery treatment process under synchrotron radiation with the passage of time using Mathematica and MATLAB according to the following plots (Figure (2)) [1-101]:
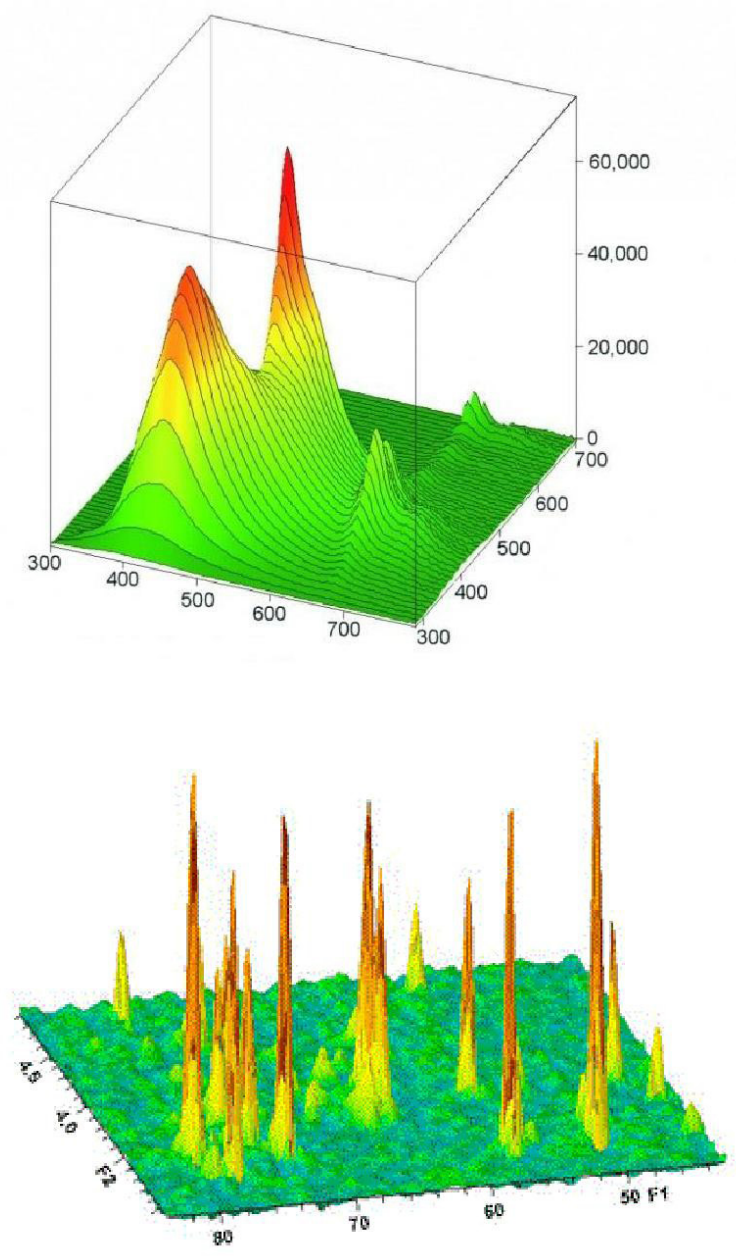

(a)

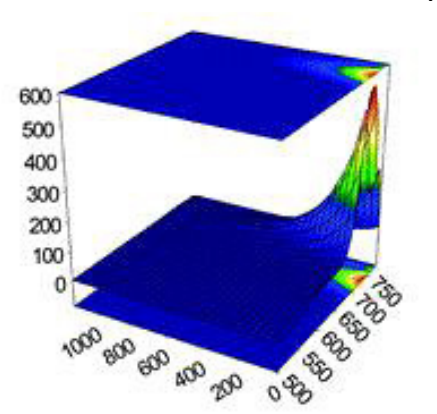

4

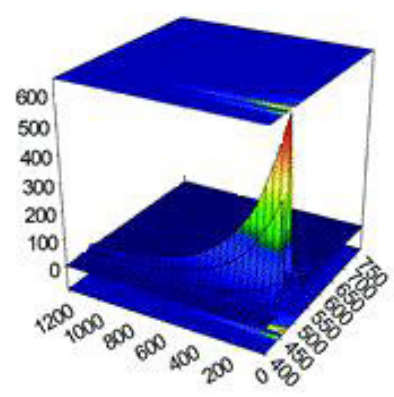

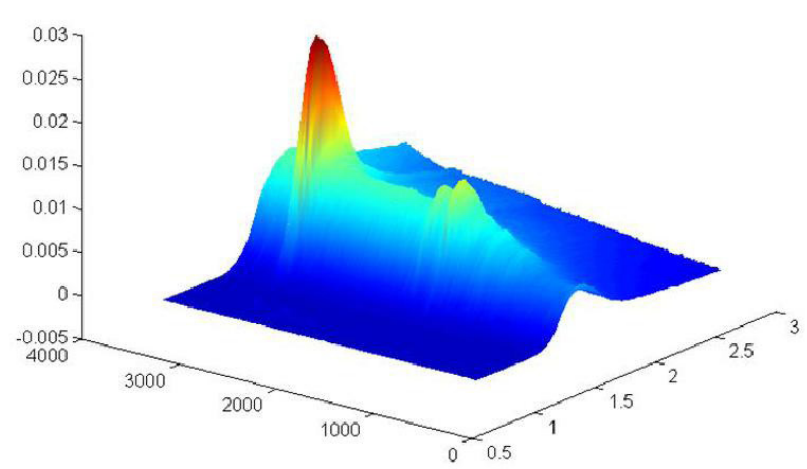

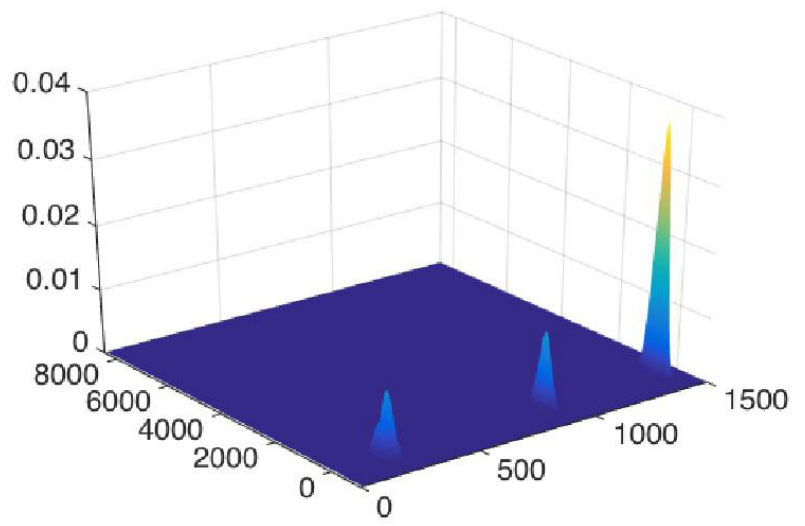

(c)

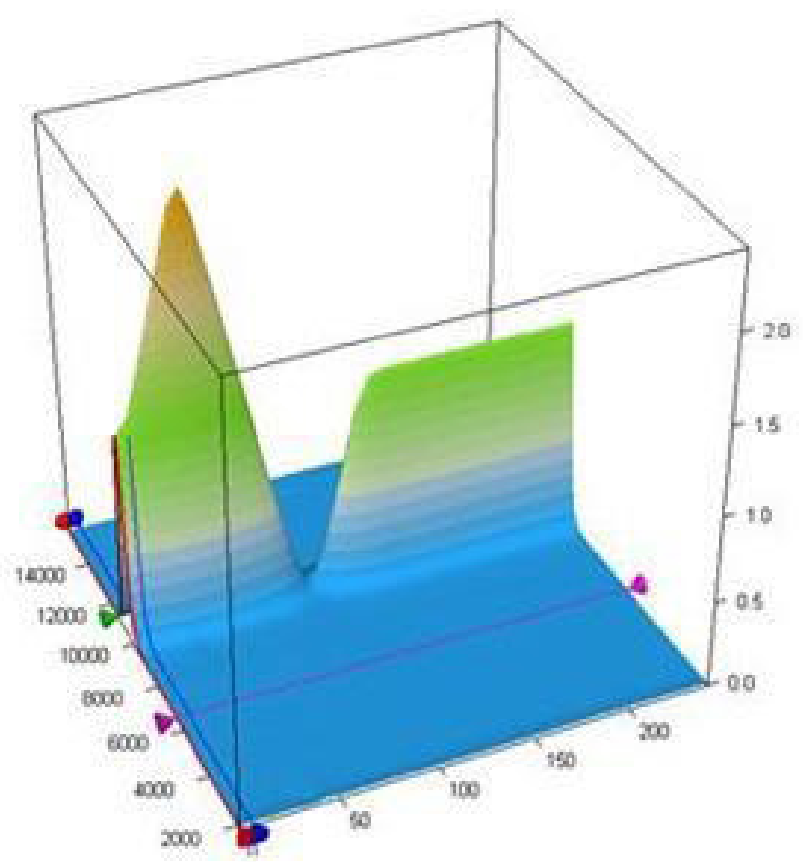

(b) 


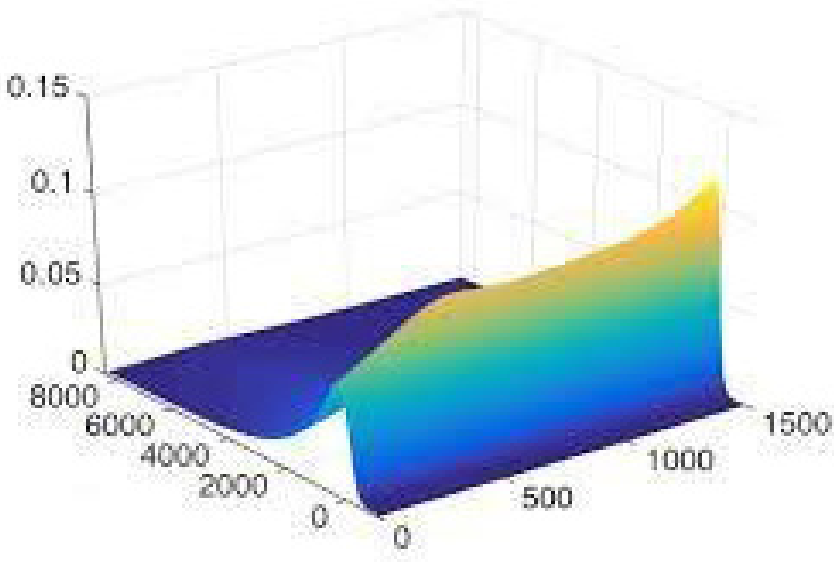

(d)

Figure 2. Different computational simulations of human brain cancer cells and tissues translational Nano drugs delivery treatment process under synchrotron radiation in therapeutic nanomedicine for human brain cancer cells and tissues using nanocarriers deliver DNA (top or left side plots) and RNA (down or right side plots) to brain tumors and (a) before irradiating of synchrotron radiation, after (b) 10 days, (c) 20 days and (d) 30 days irradiating of synchrotron radiation using Mathematica and MATLAB [1-101].

It can be concluded that malignant human brain cancer cells and tissues have gradually transformed to benign human brain cancer cells and tissues under synchrotron radiation with the passage of time (Figures 1 and 2) [1-101].

\section{6}

\section{References}

1. Heidari A, Brown C. Study of Composition and Morphology of Cadmium Oxide (CdO)Nanoparticles for Eliminating Cancer Cells. Journal of Nanomedicine Research. 2015; 2(5): 1-20.

2. Heidari A, Brown C. Study of Surface Morphological, Phytochemical and Structural Characteristics of Rhodium (III) Oxide $\left(\mathrm{Rh}_{2} \mathrm{O}_{3}\right)$ Nanoparticles. International Journal of Pharmacology. Phytochemistry and Ethnomedicine. 2015; 1: 15-19. doi: 10.18052/www.scipress.com/IJPPE.1.15

3. Heidari A. An Experimental Biospectroscopic Study on Seminal Plasma in Determination of Semen Quality for Evaluation of Male Infertility. Int J Adv Technol. 2016; 7: e007. doi: 10.4172/0976-4860.1000e007

4. Heidari A. Extraction and Preconcentration of N-Tolyl-SulfonylPhosphoramid-Saeure-Dichlorid as an Anti-Cancer Drug from Plants: A Pharmacognosy Study. J Pharmacogn Nat Prod. 2016; 2: e103. doi: 10.4172/2472-0992.1000e103

5. Heidari A. A Thermodynamic Study on Hydration and Dehydration of DNA and RNA-Amphiphile Complexes. J Bioeng Biomed Sci S. 2016; 006. doi: 10.4172/2155-9538.S3-006

6. Heidari A. Computational Studies on Molecular Structures and Carbonyl and Ketene Groups' Effects of Singlet and Triplet Energies of Azidoketene $\mathrm{O}=\mathrm{C}=\mathrm{CH}-\mathrm{NNN}$ and Isocyanatoketene $\mathrm{O}=\mathrm{C}=\mathrm{CH}-\mathrm{N}=\mathrm{C}=\mathrm{O}$. $\mathrm{J}$ Appl Computat Math. 2016; 5: e142. doi: 10.4172/2168-9679.1000e142

7. Heidari A. Study of Irradiations to Enhance the Induces the Dissociation of Hydrogen Bonds between Peptide Chains and Transition from Helix Structure to Random Coil Structure Using ATR-FTIR, Raman and HNMR Spectroscopies. J Biomol Res Ther. 2016; 5: e146. doi: 10.4172/2167$7956.1000 \mathrm{e} 146$
8. Heidari A. Future Prospects of Point Fluorescence Spectroscopy, Fluorescence Imaging and Fluorescence Endoscopy in Photodynamic Therapy (PDT) for Cancer Cells. J Bioanal Biomed. 2016; 8: e135. doi: 10.4172/1948-593X.1000e135

9. Heidari A. A Bio-Spectroscopic Study of DNA Density and Color Role as Determining Factor for Absorbed Irradiation in Cancer Cells. Adv Cancer Prev. 2016; 1: e102. doi: 10.4172/acp.1000e102

10. Heidari A. Manufacturing Process of Solar Cells Using Cadmium Oxide (CdO) and Rhodium (III) Oxide $\left(\mathrm{Rh}_{2} \mathrm{O}_{3}\right)$ Nanoparticles. J Biotechnol Biomater. 2016; 6: e125. doi: 10.4172/2155-952X.1000e125

11. Heidari A. A Novel Experimental and Computational Approach to Photobiosimulation of Telomeric DNA/RNA: A Biospectroscopic and Photobiological Study. J Res Development. 2016; 4: 144. doi: 10.4172/23113278.1000144

12. Heidari A. Biochemical and Pharmacodynamical Study of Microporous Molecularly Imprinted Polymer Selective for Vancomycin, Teicoplanin, Oritavancin, Telavancin and Dalbavancin Binding. Biochem Physiol. 2016; 5: e146. doi: 10.4172/2168-9652.1000e146

13. Heidari A. Anti-Cancer Effect of UV Irradiation at Presence of Cadmium Oxide (CdO) Nanoparticles on DNA of Cancer Cells: A Photodynamic Therapy Study. Arch Cancer Res. 2016; 4: 1.

14. Heidari A. Biospectroscopic Study on Multi-Component Reactions (MCRs) in Two A-Type and B-Type Conformations of Nucleic Acids to Determine Ligand Binding Modes, Binding Constant and Stability of Nucleic Acids in Cadmium Oxide (CdO) Nanoparticles-Nucleic Acids Complexes as AntiCancer Drugs. Arch Cancer Res. 2016; 4: 2.

15. Heidari A. Simulation of Temperature Distribution of DNA/RNA of Human Cancer Cells Using Time-Dependent Bio-Heat Equation and Nd: YAG Lasers. Arch Cancer Res. 2016; 4: 2.

16. Heidari A. Quantitative Structure-Activity Relationship (QSAR) Approximation for Cadmium Oxide (CdO) and Rhodium (III) Oxide $\left(\mathrm{Rh}_{2} \mathrm{O}_{3}\right)$ Nanoparticles as Anti-Cancer Drugs for the Catalytic Formation of Proviral DNA from Viral RNA Using Multiple Linear and Non-Linear Correlation Approach. Ann Clin Lab Res. 2016; 4: 1.

17. Heidari A. Biomedical Study of Cancer Cells DNA Therapy Using Laser Irradiations at Presence of Intelligent Nanoparticles. J Biomedical Sci. 2016; 5: 2. doi: 10.4172/2254-609X.100023

18. Heidari A. Measurement the Amount of Vitamin D2 (Ergocalciferol), Vitamin D3 (Cholecalciferol) and Absorbable Calcium ( $\left.\mathrm{Ca}^{2+}\right)$, Iron (II) $\left(\mathrm{Fe}^{2+}\right)$, Magnesium ( $\left.\mathrm{Mg}^{2+}\right)$, Phosphate ( $\left.\mathrm{PO}^{4-}\right)$ and Zinc $\left(\mathrm{Zn}^{2+}\right)$ in Apricot Using High-Performance Liquid Chromatography (HPLC) and Spectroscopic Techniques. J Biom Biostat. 2016; 7: 292. doi: 10.4172/2155-6180.1000292

19. Heidari A. Spectroscopy and Quantum Mechanics of the Helium Dimer $\left(\mathrm{He}^{2+}\right)$, Neon Dimer $\left(\mathrm{Ne}^{2+}\right)$, Argon Dimer $\left(\mathrm{Ar}^{2+}\right)$, Krypton Dimer $\left(\mathrm{Kr}^{2+}\right)$, Xenon Dimer $\left(\mathrm{Xe}^{2+}\right)$, Radon Dimer $\left(\mathrm{Rn}^{2+}\right)$ and Ununoctium Dimer (Uuo $\left.{ }^{2+}\right)$ Molecular Cations. Chem Sci J. 2016; 7: e112. doi: 10.4172/2150-3494.1000e112

20. Heidari A. Human Toxicity Photodynamic Therapy Studies on DNA/RNA Complexes as a Promising New Sensitizer for the Treatment of Malignant Tumors Using Bio-Spectroscopic Techniques. J Drug Metab Toxicol. 2016; 7: e129. doi: 10.4172/2157-7609.1000e129

21. Heidari A. Novel and Stable Modifications of Intelligent Cadmium Oxide (CdO) Nanoparticles as Anti-Cancer Drug in Formation of Nucleic Acids Complexes for Human Cancer Cells Treatment. Biochem Pharmacol (Los Angel). 2016; 5: 207. doi: 10.4172/2167-0501.1000207

22. Heidari A. A Combined Computational and QM/MM Molecular Dynamics Study on Boron Nitride Nanotubes (BNNTs), Amorphous Boron Nitride Nanotubes (a-BNNTs) and Hexagonal Boron Nitride Nanotubes (h-BNNTs) as Hydrogen Storage. Struct Chem Crystallogr Commun. 2016; 2: 1.

23. Heidari A. Pharmaceutical and Analytical Chemistry Study of Cadmium Oxide (CdO) Nanoparticles Synthesis Methods and Properties as AntiCancer Drug and its Effect on Human Cancer Cells. Pharm Anal Chem. 2016; 2: 113. doi: 10.4172/2471-2698.1000113 
24. Heidari A. A Chemotherapeutic and Biospectroscopic Investigation of the Interaction of Double-Standard DNA/RNA-Binding Molecules with Cadmium Oxide (CdO) and Rhodium (III) Oxide $\left(\mathrm{Rh}_{2} \mathrm{O}_{3}\right)$ Nanoparticles as Anti-Cancer Drugs for Cancer Cells' Treatment. Chemo Open Access. 2016; 5: e129. doi: 10.4172/2167-7700.1000e129

25. Heidari A. Pharmacokinetics and Experimental Therapeutic Study of DNA and Other Biomolecules Using Lasers: Advantages and Applications. J Pharmacokinet Exp Ther. 2016; 1: e005. doi: 10.4172/jpet.1000e005

26. Heidari A. Determination of Ratio and Stability Constant of DNA/RNA in Human Cancer Cells and Cadmium Oxide (CdO) Nanoparticles Complexes Using Analytical Electrochemical and Spectroscopic Techniques. Insights Anal Electrochem. 2016; 2: 1.

27. Heidari A. Discriminate between Antibacterial and Non-Antibacterial Drugs Artificial Neutral Networks of a Multilayer Perceptron (MLP) Type Using a Set of Topological Descriptors. J Heavy Met Toxicity Dis. 2016; 1: 2. doi: 10.21767/2473-6457.100009

28. Heidari A. Combined Theoretical and Computational Study of the Belousov-Zhabotinsky Chaotic Reaction and Curtius Rearrangement for Synthesis of Mechlorethamine, Cisplatin, Streptozotocin, Cyclophosphamide, Melphalan, Busulphan and BCNU as Anti-Cancer Drugs. Insights Med Phys. 2016; 1: 2.

29. Heidari A. A Translational Biomedical Approach to Structural Arrangement of Amino Acids' Complexes: A Combined Theoretical and Computational Study. Transl Biomed. 2016; 7: 2.

30. Heidari A. Ab Initio and Density Functional Theory (DFT) Studies of Dynamic NMR Shielding Tensors and Vibrational Frequencies of DNA/RNA and Cadmium Oxide (CdO) Nanoparticles Complexes in Human Cancer Cells. J Nanomedine Biotherapeutic Discov. 2016; 6: e144. doi: 10.4172/2155-983X.1000e144

31. Heidari A. Molecular Dynamics and Monte-Carlo Simulations for Replacement Sugars in Insulin Resistance, Obesity, LDL Cholesterol, Triglycerides, Metabolic Syndrome, Type 2 Diabetes and Cardiovascular Disease: A Glycobiological Study. J Glycobiol. 2016; 5: e111. doi: 10.4172/2168-958X.1000e111

32. Heidari A. Synthesis and Study of 5-[(Phenylsulfonyl)Amino]-1,3,4Thiadiazole-2-Sulfonamide as Potential Anti-Pertussis Drug Using Chromatography and Spectroscopy Techniques. Transl Med (Sunnyvale). 2016; 6: e138. doi: 10.4172/2161-1025.1000e137

33. Heidari A. Nitrogen, Oxygen, Phosphorus and Sulphur Heterocyclic AntiCancer Nano Drugs Separation in the Supercritical Fluid of Ozone $\left(\mathrm{O}_{3}\right)$ Using Soave-Redlich-Kwong (SRK) and Pang-Robinson (PR) Equations. Electronic J Biol. 2016; 12: 4

34. Heidari A. An Analytical and Computational Infrared Spectroscopic Review of Vibrational Modes in Nucleic Acids. Austin J Anal Pharm Chem. 2016; 3(1): 1058.

35. Heidari A, Brown C. Phase, Composition and Morphology Study and Analysis of Os-Pd/HfC Nanocomposites. Nano Res Appl. 2016; 2: 1.

36. Heidari A, Brown C. Vibrational Spectroscopic Study of Intensities and Shifts of Symmetric Vibration Modes of Ozone Diluted by Cumene. International Journal of Advanced Chemistry. 2016; 4(1): 5-9. doi: 10.14419/ ijac.v4i1.6080

37. Heidari A. Study of the Role of Anti-Cancer Molecules with Different Sizes for Decreasing Corresponding Bulk Tumor Multiple Organs or Tissues. Arch Can Res. 2016; 4: 2.

38. Heidari A. Genomics and Proteomics Studies of Zolpidem, Necopidem, Alpidem, Saripidem, Miroprofen, Zolimidine, Olprinone and Abafungin as Anti-Tumor, Peptide Antibiotics, Antiviral and Central Nervous System (CNS) Drugs. J Data Mining Genomics \& Proteomics. 2016; 7: e125. doi: 10.4172/2153-0602.1000e125

39. Heidari A. Pharmacogenomics and Pharmacoproteomics Studies of Phosphodiesterase-5 (PDE5) Inhibitors and Paclitaxel Albumin-Stabilized Nanoparticles as Sandwiched Anti-Cancer Nano Drugs between Two DNA/ RNA Molecules of Human Cancer Cells. J Pharmacogenomics Pharmacoproteomics. 2016; 7: e153. doi: 10.4172/2153-0645.1000e153
40. Heidari A. Biotranslational Medical and Biospectroscopic Studies of Cadmium Oxide (CdO) Nanoparticles-DNA/RNA Straight and Cycle Chain Complexes as Potent Anti-Viral, Anti-Tumor and Anti-Microbial Drugs: A Clinical Approach. Transl Biomed. 2016; 7: 2.

41. Heidari A. A Comparative Study on Simultaneous Determination and Separation of Adsorbed Cadmium Oxide (CdO) Nanoparticles on DNA/ RNA of Human Cancer Cells Using Biospectroscopic Techniques and Dielectrophoresis (DEP) Method. Arch Can Res. 2016; 4: 2

42. Heidari A. Cheminformatics and System Chemistry of Cisplatin, Carboplatin, Nedaplatin, Oxaliplatin, Heptaplatin and Lobaplatin as Anti-Cancer Nano Drugs: A Combined Computational and Experimental Study. J Inform Data Min. 2016; 1: 3. doi: 10.21767/2472-1956.100015

43. Heidari A. Linear and Non-Linear Quantitative Structure-Anti-CancerActivity Relationship (QSACAR) Study of Hydrous Ruthenium (IV) Oxide $\left(\mathrm{RuO}_{2}\right)$ Nanoparticles as Non-Nucleoside Reverse Transcriptase Inhibitors (NNRTIs) and Anti-Cancer Nano Drugs. J Integr Oncol. 2016; 5: e110. doi: $10.4172 / 2329-6771.1000 \mathrm{e} 110$

44. Heidari A. Synthesis, Characterization and Biospectroscopic Studies of Cadmium Oxide (CdO) Nanoparticles-Nucleic Acids Complexes Absence of Soluble Polymer as a Protective Agent Using Nucleic Acids Condensation and Solution Reduction Method. J Nanosci Curr Res. 2016; 1: e101.

45. Heidari A. Coplanarity and Collinearity of 4'-Dinonyl-2,2'-Bithiazole in One Domain of Bleomycin and Pingyangmycin to be Responsible for Binding of Cadmium Oxide (CdO) Nanoparticles to DNA/RNA Bidentate Ligands as Anti-Tumor Nano Drug. Int J Drug Dev \& Res. 2016; 8: 007-008.

46. Heidari A. A Pharmacovigilance Study on Linear and Non-Linear Quantitative Structure (Chromatographic) Retention Relationships (QSRR) Models for the Prediction of Retention Time of Anti-Cancer Nano Drugs under Synchrotron Radiations. J Pharmacovigil. 2016; 4: e161. doi: 10.4172/2329-6887.1000e161

47. Heidari A. Nanotechnology in Preparation of Semipermeable Polymers. $J$ Adv Chem Eng. 2016; 6: 157.

48. Heidari A. A Gastrointestinal Study on Linear and Non-Linear Quantitative Structure (Chromatographic) Retention Relationships (QSRR) Models for Analysis 5-Aminosalicylates Nano Particles as Digestive System Nano Drugs under Synchrotron Radiations. J Gastrointest Dig Syst. 2016; 6: e119. doi: 10.4172/2161-069X.1000e119

49. Heidari A. DNA/RNA Fragmentation and Cytolysis in Human Cancer Cells Treated with Diphthamide Nano Particles Derivatives. Biomedical Data Mining. 2016; 5: e102. doi: 10.4172/2090-4924.1000e102

50. Heidari A. A Successful Strategy for the Prediction of Solubility in the Construction of Quantitative Structure-Activity Relationship (QSAR) and Quantitative Structure-Property Relationship (QSPR) under Synchrotron Radiations Using Genetic Function Approximation (GFA) Algorithm. J Mol Biol Biotechnol. 2016; 1: 1.

51. Heidari A. Computational Study on Molecular Structures of $C_{20}, C_{60}, C_{240}$ $C_{540}, C_{960}, C_{2160}$ and $C_{3840}$ Fullerene Nano Molecules under Synchrotron Radiations Using Fuzzy Logic. J Material Sci Eng. 2016; 5: 282. doi: 10.4172/2169-0022.1000282

52. Heidari A. Graph Theoretical Analysis of Zigzag Polyhexamethylene Biguanide, Polyhexamethylene Adipamide, Polyhexamethylene Biguanide Gauze and Polyhexamethylene Biguanide Hydrochloride (PHMB) Boron Nitride Nanotubes (BNNTs), Amorphous Boron Nitride Nanotubes (a-BNNTs) and Hexagonal Boron Nitride Nanotubes (h-BNNTs). J Appl Computat Math. 2016; 5: e143. doi: 10.4172/2168-9679.1000e143

53. Heidari A. The Impact of High Resolution Imaging on Diagnosis. Int J Clin Med Imaging. 2016; 3: 1000e101.

54. Heidari A. A Comparative Study of Conformational Behavior of Isotretinoin (13-Cis Retinoic Acid) and Tretinoin (All-Trans Retinoic Acid (ATRA)) Nano Particles as Anti-Cancer Nano Drugs under Synchrotron Radiations Using Hartree-Fock (HF) and Density Functional Theory (DFT) Methods. Insights in Biomed. 2016; 1: 2.

55. Heidari A. Advances in Logic, Operations and Computational Mathematics. J Appl Computat Math. 2016; 5: e144. doi: 10.4172/2168-9679.1000e144 
56. Heidari A. Mathematical Equations in Predicting Physical Behavior. J App Computat Math. 2016; 5: e145. doi: 10.4172/2168-9679.1000e145

57. Heidari A. Chemotherapy a Last Resort for Cancer Treatment. Chemo Open Access. 2016; 5: 4. doi: 10.4172/2167-7700.1000e130

58. Heidari A. Separation and Pre-Concentration of Metal Cations-DNA/RNA Chelates Using Molecular Beam Mass Spectrometry with Tunable Vacuum Ultraviolet (VUV) Synchrotron Radiation and Various Analytical Methods. Mass Spectrom Purif Tech. 2016; 2: e101. doi: 10.4172/2469-9861.1000e101

59. Heidari A. Yoctosecond Quantitative Structure-Activity Relationship (QSAR) and Quantitative Structure-Property Relationship (QSPR) under Synchrotron Radiations Studies for Prediction of Solubility of Anti-Cancer Nano Drugs in Aqueous Solutions Using Genetic Function Approximation (GFA) Algorithm. Insight Pharm Res. 2016; 1: 1.

60. Heidari A. Cancer Risk Prediction and Assessment in Human Cells under Synchrotron Radiations Using Quantitative Structure Activity Relationship (QSAR) and Quantitative Structure Properties Relationship (QSPR) Studies. Int J Clin Med Imaging. 2016; 3: 516

61. Heidari A. A Novel Approach to Biology. Electronic J Biol. 2016; 12: 3.

62. Heidari A. Innovative Biomedical Equipment's for Diagnosis and Treatment. $J$ Bioengineer \& Biomedical Sci. 2016; 6: e123. doi: 10.4172/2155-9538.1000e125

63. Heidari A. Integrating Precision Cancer Medicine into Healthcare, Medicare Reimbursement Changes and the Practice of Oncology: Trends in Oncology Medicine and Practices. J Oncol Med \& Pract. 2016; 1: 2.

64. Heidari A. Promoting Convergence in Biomedical and Biomaterials Sciences and Silk Proteins for Biomedical and Biomaterials Applications: An Introduction to Materials in Medicine and Bioengineering Perspectives. J Bioengineer \& Biomedical Sci. 2016; 6: 3. doi: 10.4172/2155-9538.1000e126

65. Heidari A. X-Ray Fluorescence and X-Ray Diffraction Analysis on Discrete Element Modeling of Nano Powder Metallurgy Processes in Optimal Container Design. J Powder Metall Min. 2017; 6: 1. doi: 10.4172/2168-9806.1000e136

66. Heidari A. Biomolecular Spectroscopy and Dynamics of Nano-Sized Molecules and Clusters as Cross-Linking-Induced Anti-Cancer and Immune-Oncology Nano Drugs Delivery in DNA/RNA of Human Cancer Cells'Membranes under Synchrotron Radiations: A Payload-Based Perspective. Arch Chem Res. 2017; 1: 2. doi: 10.21767/2572-4657.100011

67. Heidari A. Deficiencies in Repair of Double-Standard DNA/RNA-Binding Molecules Identified in Many Types of Solid and Liquid Tumors Oncology in Human Body for Advancing Cancer Immunotherapy Using Computer Simulations and Data Analysis. J Appl Bioinforma Comput Biol. 2017; 6: 1. doi: 10.4172/2329-9533.1000e104

68. Heidari A. Electronic Coupling among the Five Nanomolecules Shuts Down Quantum Tunneling in the Presence and Absence of an Applied Magnetic Field for Indication of the Dimer or other Provide Different Influences on the Magnetic Behavior of Single Molecular Magnets (SMMs) as Qubits for Quantum Computing. Glob J Res Rev. 2017; 4: 2.

69. Heidari A. Polymorphism in Nano-Sized Graphene Ligand-Induced Transformation of Au38-xAgx/xCux(SPh-tBu)24 to Au36-xAgx/xCux(SPh$\mathrm{tBu} 24(\mathrm{x}=1-12) \quad$ Nanomolecules for Synthesis of Au144-xAgx/ xCux[(SR)60,(SC4)60，(SC6)60， (SC12)60,(PET)60， (p-MBA)60， (F)60， (Cl)60,(Br)60, (I)60, (At)60, (Uus)60 and (SC6H13)60] Nano. J Nanomater Mol Nanotechnol. 2017; 6: 3. doi: 10.4172/2324-8777.1000e109

70. Heidari A. Biomedical Resource Oncology and Data Mining to Enable Resource Discovery in Medical, Medicinal, Clinical, Pharmaceutical, Chemical and Translational Research and Their Applications in Cancer Research. Int J Biomed Data Min. 2017; 6: e103. doi: 10.4172/2090-4924.1000e103

71. Heidari A. Study of Synthesis, Pharmacokinetics, Pharmacodynamics, Dosing, Stability, Safety and Efficacy of Olympiadane Nanomolecules as Agent for Cancer Enzymotherapy, Immunotherapy, Chemotherapy, Radiotherapy, Hormone Therapy and Targeted Therapy under Synchrotorn Radiation. J Dev Drugs. 2017; 6: e154.

72. Heidari A. A Novel Approach to Future Horizon of Top Seven Biomedical Research Topics to Watch in 2017: Alzheimer's, Ebola, Hypersomnia, Human Immunodeficiency Virus (HIV), Tuberculosis (TB), Microbiome/ Antibiotic Resistance and Endovascular Stroke. J Bioengineer \& Biomedical Sci. 2017; 7: e127. doi: 10.4172/2155-9538.1000e127
73. Heidari A. Opinion on Computational Fluid Dynamics (CFD) Technique Fluid Mech Open Acc. 2017; 4: 157. doi: 10.4172/2476-2296.1000157

74. Heidari A. Concurrent Diagnosis of Oncology Influence Outcomes in Emergency General Surgery for Colorectal Cancer and Multiple Sclerosis (MS) Treatment Using Magnetic Resonance Imaging (MRI) and Au329(SR)84, Au329-xAgx(SR)84, Au144(SR)60, Au68(SR)36, Au30(SR)18 Au102(SPh)44, Au38(SPh)24, Au38(SC2H4Ph)24, Au21S(SAdm)15 Au36(pMBA)24 and Au25(pMBA)18 Nano Clusters. J Surgery Emerg Med. 2017; $1: 21$.

75. Heidari A. Developmental Cell Biology in Adult Stem Cells Death and Autophagy to Trigger a Preventive Allergic Reaction to Common Airborne Allergens under Synchrotron Radiation Using Nanotechnology for Therapeutic Goals in Particular Allergy Shots (Immunotherapy). Cell Biol (Henderson, NV). 2017; 6: 1. doi: 10.4172/2324-9293.1000e117

76. Heidari A. Changing Metal Powder Characteristics for Elimination of the Heavy Metals Toxicity and Diseases in Disruption of Extracellular Matrix (ECM) Proteins Adjustment in Cancer Metastases Induced by Osteosarcoma, Chondrosarcoma, Carcinoid, Carcinoma, Ewing's Sarcoma, Fibrosarcoma and Secondary Hematopoietic Solid or Soft Tissue Tumors. J Powder Metall Min. 2017; 6: 170. doi: 10.4172/2168-9806.1000170

77. Heidari A. Nanomedicine-Based Combination Anti-Cancer Therapy between Nucleic Acids and Anti-Cancer Nano Drugs in Covalent Nano Drugs Delivery Systems for Selective Imaging and Treatment of Human Brain Tumors Using Hyaluronic Acid, Alguronic Acid and Sodium Hyaluronate as Anti-Cancer Nano Drugs and Nucleic Acids Delivery under Synchrotron Radiation. Am J Drug Deliv. 2017; 5: 2.

78. Heidari A. Clinical Trials of Dendritic Cell Therapies for Cancer Exposing Vulnerabilities in Human Cancer Cells' Metabolism and Metabolomics: New Discoveries, Unique Features Inform New Therapeutic Opportunities, Biotech's Bumpy Road to the Market and Elucidating the Biochemical Programs that Support Cancer Initiation and Progression. J Biol Med Science. 2017; 1: e103

79. Heidari A. The Design Graphene-Based Nanosheets as a New Nanomaterial in Anti-Cancer Therapy and Delivery of Chemotherapeutics and Biological Nano Drugs for Liposomal Anti-Cancer Nano Drugs and Gene Delivery. $\mathrm{Br}$ Biomed Bull. 2017; 5: 305. doi: 10.21767/2471-9897.1000305

80. Heidari A. Integrative Approach to Biological Networks for Emerging Roles of Proteomics, Genomics and Transcriptomics in the Discovery and Validation of Human Colorectal Cancer Biomarkers from DNA/RNA Sequencing Data under Synchrotron Radiation. Transcriptomics 5. 2017; 13: e117.

81. Heidari A. Elimination of the Heavy Metals Toxicity and Diseases in Disruption of Extracellular Matrix (ECM) Proteins and Cell Adhesion Intelligent Nanomolecules Adjustment in Cancer Metastases Using Metalloenzymes and under Synchrotron Radiation. Lett Health Biol Sci. 2017; 2(2): 1-4

82. Heidari A. Treatment of Breast Cancer Brain Metastases through a Targeted Nanomolecule Drug Delivery System Based on Dopamine Functionalized Multi-Wall Carbon Nanotubes (MWCNTs) Coated with Nano Graphene Oxide (GO) and Protonated Polyaniline (PANI) in Situ During the Polymerization of Aniline Autogenic Nanoparticles for the Delivery of AntiCancer Nano Drugs under Synchrotron Radiation. Br J Res. 2017; 4(3): 16. doi: 10.21767/2394-3718.100016

83. Heidari A. Sedative, Analgesic and Ultrasound-Mediated Gastrointestinal Nano Drugs Delivery for Gastrointestinal Endoscopic Procedure, Nano Drug-Induced Gastrointestinal Disorders and Nano Drug Treatment of Gastric Acidity. Res Rep Gastroenterol. 2017; 1: 1.

84. Heidari A. Synthesis, Pharmacokinetics, Pharmacodynamics, Dosing, Stability, Safety and Efficacy of Orphan Nano Drugs to Treat High Cholesterol and Related Conditions and to Prevent Cardiovascular Disease under Synchrotron Radiation. J Pharm Sci Emerg Drugs. 2017; 5: 1. doi: 10.4172/2380-9477.1000e104

85. Heidari A. Non-Linear Compact Proton Synchrotrons to Improve Human Cancer Cells and Tissues Treatments and Diagnostics through Particle Therapy Accelerators with Monochromatic Microbeams. J Cell Biol Mol Sci. 2017; 2(1): 1-5. 
86. Heidari A. Design of Targeted Metal Chelation Therapeutics Nanocapsules as Colloidal Carriers and Blood-Brain Barrier (BBB) Translocation to Targeted Deliver Anti-Cancer Nano Drugs into the Human Brain to Treat Alzheimer's Disease under Synchrotron Radiation. J Nanotechnol Material Sci. 2017; 4(2): 1-5.

87. Gobato R, Heidari A. Calculations Using Quantum Chemistry for Inorganic Molecule Simulation BeLi2SeSi", American Journal of Quantum Chemistry and Molecular Spectroscopy. 2017; 2(3): 37-46.

88. Heidari A. Different High-Resolution Simulations of Medical, Medicinal, Clinical, Pharmaceutical and Therapeutics Oncology of Human Lung Cancer Translational Anti-Cancer Nano Drugs Delivery Treatment Process under Synchrotron and X-Ray Radiations. J Med Oncol. 2017; 1(1): 1.

89. Heidari A. A Modern Ethnomedicinal Technique for Transformation, Prevention and Treatment of Human Malignant Gliomas Tumors into Human Benign Gliomas Tumors under Synchrotron Radiation. Am J Ethnomed. 2017; 4(1): 10.

90. Heidari A. An Investigation of the Role of DNA as Molecular Computers: A Computational Study on the Hamiltonian Path Problem. International Journal of Scientific \& Engineering Research. 2014; 5(1): 1884-1889.

91. Heidari A. Active Targeted Nanoparticles for Anti-Cancer Nano Drugs Delivery across the Blood-Brain Barrier for Human Brain Cancer Treatment, Multiple Sclerosis (MS) and Alzheimer's Diseases Using Chemical Modifications of Anti-Cancer Nano Drugs or Drug-Nanoparticles through Zika Virus (ZIKV) Nanocarriers under Synchrotron Radiation. J Med Chem Toxicol. 2017; 2(3): 1-5.

92. Heidari A. Investigation of Medical, Medicinal, Clinical and Pharmaceutical Applications of Estradiol, Mestranol (Norlutin), Norethindrone (NET), Norethisterone Acetate (NETA), Norethisterone Enanthate (NETE) and Testosterone Nanoparticles as Biological Imaging, Cell Labeling, AntiMicrobial Agents and Anti-Cancer Nano Drugs in Nanomedicines Based Drug Delivery Systems for Anti-Cancer Targeting and Treatment. Parana Journal of Science and Education (PJSE). 2017; 3(4): 10-19.

93. Heidari A. A Comparative Computational and Experimental Study on Different Vibrational Biospectroscopy Methods, Techniques and Applications for Human Cancer Cells in Tumor Tissues Simulation, Modeling, Research, Diagnosis and Treatment. Open J Anal Bioanal Chem. 2017; 1(1): 014-020.
94. Heidari A. Combination of DNA/RNA Ligands and Linear/Non-Linear Visible-Synchrotron Radiation-Driven N-Doped Ordered Mesoporous Cadmium Oxide (CdO) Nanoparticles Photocatalysts Channels Resulted in an Interesting Synergistic Effect Enhancing Catalytic Anti-Cancer Activity. Enz Eng. 2017; 6: 1.

95. Heidari A. Modern Approaches in Designing Ferritin, Ferritin Light Chain, Transferrin, Beta-2 Transferrin and Bacterioferritin-Based Anti-Cancer Nano Drugs Encapsulating Nanosphere as DNA-Binding Proteins from Starved Cells (DPS). Mod Appro Drug Des. 2017; 1(1): 000504.

96. Heidari A. Potency of Human Interferon $\beta-1 a$ and Human Interferon $\beta-1 b$ in Enzymotherapy, Immunotherapy, Chemotherapy, Radiotherapy, Hormone Therapy and Targeted Therapy of Encephalomyelitis Disseminate/Multiple Sclerosis (MS) and Hepatitis A, B, C, D, E, F and G Virus Enter and Targets Liver Cells. J Proteomics Enzymol:: 2017; 6: 1.

97. Heidari A. Transport Therapeutic Active Targeting of Human Brain Tumors Enable Anti-Cancer Nanodrugs Delivery across the Blood-Brain Barrier (BBB) to Treat Brain Diseases Using Nanoparticles and Nanocarriers under Synchrotron Radiation. J Pharm Pharmaceutics. 2017; 4(2): 1-5.

98. Heidari A, Brown C. Combinatorial Therapeutic Approaches to DNA/RNA and Benzylpenicillin (Penicillin G), Fluoxetine Hydrochloride (Prozac and Sarafem), Propofol (Diprivan), Acetylsalicylic Acid (ASA) (Aspirin), Naproxen Sodium (Aleve and Naprosyn) and Dextromethamphetamine Nanocapsules with Surface Conjugated DNA/RNA to Targeted Nano Drugs for Enhanced Anti-Cancer Efficacy and Targeted Cancer Therapy Using Nano Drugs Delivery Systems. Ann Adv Chem. 2017; 1(2): 061-069.

99. Heidari A. Vibrational Spectroscopy of Nucleic Acids", Wahid Ali Khan (Editor), "Basic Biochemistry", Austin Publishing Group (APG)/Austin Publications LLC, ISBN: 978-0-9971499-2-0, Pages 1-18, Jersey City, New Jersey, USA, 2016.

100. Heidari A. High-Resolution Simulations of Human Brain Cancer Translational Nano Drugs Delivery Treatment Process under Synchrotron Radiation. J Transl Res. 2017; 1(1): 1-3.

101. Heidari A. Investigation of Anti-Cancer Nano Drugs' Effects' Trend on Human Pancreas Cancer Cells and Tissues Prevention, Diagnosis and Treatment Process under Synchrotron and X-Ray Radiations with the Passage of Time Using Mathematica. Current Trends Anal Bioanal Chem. 2017; 1(1): 36-41. 